\title{
THE ASSESSMENT OF OBJECT USABILITY ON THE BASIS OF INSTANTANEOUS VALUES OF TECHNICAL CONDITION AND REGULATION STATE PARAMETERS
}

\author{
Paweł Lindstedt \\ Bialystok University of Technology, Faculty of Mechanical Engineering \\ Wiejska Street 45C, 15 - 351 Bialystok, Poland \\ tel.: +4885 7469220, fax: +48857469210 \\ e-mail:p.lindstedt@pb.edu.pl
}

Tomasz Sudakowski

Bialystok Water Supply LTD, Faculty of Mechanical Engineering

Mlynowa Street 52/1, 15-404 Bialystok, Poland

e-mail:sudak@plusnet.pl

\begin{abstract}
In the process of using a complex technical object, it is deregulated, worn and its reliability is decreased. Therefore, it is required that its status, technical state and reliability should be observed during its normal use and handling. The results of such observations allow a synthetic (complex) assessment of suitability of the object, determining its ability to properly carry out its tasks in accordance with its intended purpose. A continuous observation of changes of technical condition on the basis of relationship between the diagnostic signals (output) and the input signals (environment) allow evaluation of the regulation state of the object [4, 5].

An innovative method of assessment of the operated system usability presented in the article concerns an adequate analysis of the changes to $a_{R b}$ technical condition and $a_{R c}$, regulation state current parameters formed from coupled equations of state (1 and 2) [1, 2, 3, 7]. While analysing the waveforms of instantaneous values of $a_{R b}$ technical condition and $a_{R c}$ regulation state parameters, it has been observed that parameter and instantaneous damage can be identified on the basis of quantitative relationships between the instantaneous threshold value of $d_{p r}$ and the

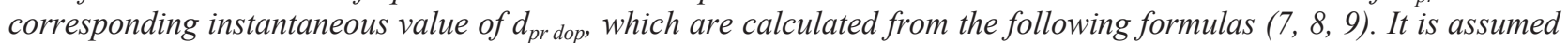
that damage exists if for the instant $\theta_{i}: d_{p_{i}}>d_{p r i p_{p}}$. Having the quantity of damage, reliability characteristics can be determined for every time of technical object exploitation (prior to the occurrence of catastrophic damage) [6].
\end{abstract}

Keywords: parametric damage, instant damage, technical condition parameter, state regulation parameter, reliability characteristics

\section{Introduction}

In the process of using a complex technical object, it is deregulated, worn and its reliability is decreased. Therefore, it is required that its status, technical state and reliability should be observed during its normal use and handling. The results of such observations allow a synthetic (complex) assessment of suitability of the object, determining its ability to properly carry out its tasks in accordance with its intended purpose.

A continuous observation of changes of technical condition on the basis of relationship between the diagnostic signals (output) and the input signals (environment) allow evaluation of the regulation state of the object $[4,5]$.

A continuous observation of changes of technical condition parameters on the basis of relationship between the diagnostic signals associated with the wear of components and accompanying ambient signals is possible due to diagnostics of the object [4].

A continuous accumulation of knowledge about the damage to the object that represents level limits 
of deregulation and wear of the object, and then (according to PN-77/N-04005) conversion of such identified number of defects into reliability characteristics, allow to test the reliability of the object.

The assessments of regulatory, diagnostics and reliability states are basic, closely related elements, which, in the cybernetic system of operation, constitute the basis for a comprehensive assessment of the suitability of the object $[1,6,7]$.

The method described in the article concerning the evaluation of the object usability is based on an adequate analysis of changes of current values of $\mathrm{aRb}$ technical condition and aRc state regulation parameters set from interactive, coupled equations of state $[5,7]$.

It was discovered that the analysis of the value of $\mathrm{aRb}$ technical condition and aRc state regulation parameters could identify the defects (parametric and temporary respectively) on the basis of quantitative relationship between the instantaneous $d_{p r}$ threshold values $\left(a_{R b}, a_{R c}\right.$ parameter $)$ and corresponding instantaneous $d_{\text {prdop }}$ permissible values.

\section{Theoretical basis of the assessment of technical object suitability}

The assessment of the usability of the object is based on the assumption that each technical object in the environment is described by two correlated equations of state $[5,7]$ :

$$
\begin{aligned}
& \frac{\Delta D_{K}}{\Delta \Theta}=a_{R_{b}} D_{K}+b_{R_{b}} U, \\
& \frac{\Delta Y}{\Delta \Theta}=a_{R_{c}} U+b_{R_{c}} D_{K},
\end{aligned}
$$

where:

$D_{K}$ - comprehensive diagnostic signal,

$U$ - comprehensive utility signal (operation),

$a_{R b}-$ technical condition parameter,

$a_{R c}$ - the parameter of the state of regulation (use),

$b_{R b}$ - the parameter of quality of use impact on technical condition,

$b_{R c}$ - the parameter of quality of technical condition impact on the state of operation,

$\Delta \Theta-$ increase in operation life.

These equations are based on the obvious observation that the value of use (operation) of an object depends on technical condition (physical wear and tear), and technical condition depends on the intensity of use and regulation quality, i.e. DK technical condition is an environment for the U state of usability and vice versa.

$\mathrm{aRb}$ technical condition and $\mathrm{aRc}$ state regulation parameters are calculated from the equations of state (1 and 2):

$$
\begin{aligned}
& a_{R_{b}}=\frac{\Delta D_{K}}{\Delta \Theta\left(D_{K}+\hat{a}_{R_{b}} U\right)}, \\
& a_{R c}=\frac{\Delta U}{\Delta \Theta\left(U+a_{R_{c}} D_{K}\right)},
\end{aligned}
$$

where:

$$
\begin{gathered}
a_{R_{b}}=-\frac{\sum_{i=1}^{n} \Delta D_{K_{i}} \Delta U_{i},}{\sum_{i=1}^{n} \Delta U_{i}^{2}}, \\
a_{R_{e}}=-\frac{\sum_{i=1}^{n} \Delta D_{K_{i}} \Delta U_{i}}{\sum_{i=1}^{n} \Delta D_{K_{i}}{ }^{2}},
\end{gathered}
$$

From the correlations of (3 and 4), it can be inferred that at any time $\Theta_{i}+\Delta \Theta(\Delta \Theta-$ sufficiently 
large) can be calculated from the instantaneous values of $a_{R b}$ and $a_{R c}$, which constitute the basis for quantitative evaluation of technical condition and regulation state. In addition, the strings of, $a_{R b}(\theta)$ and $a_{R b}(\theta)$ values can constitute the basis for the identification of parametric and instantaneous damage, and, therefore, reliability characteristics (before the onset of catastrophic damage).

In order to accurately determine the technical parameters, the threshold characteristics of a diagnostic signal from correlation (7), the limit value of a summary diagnostic signal (8) and the limit value of $a_{R b}$ and $a_{R c}$ parameters (9) should be determined.

$$
\begin{gathered}
d_{p r}(\Theta)=i \cdot \mu+a \cdot \sigma \cdot \sqrt{i}, \\
d_{p r}(\Theta)=i \cdot \mu+a \cdot \sigma \cdot \sqrt{i}, \\
d_{p r c o p}=\frac{\Theta_{i}}{\Theta_{\max }} d_{d o p},
\end{gathered}
$$

where:

$d_{p r}(\theta)$ - the threshold of $a_{R b}$ and $a_{R c}$ parameters,

$d_{d o p} \quad-$ limit values of $a_{R b}$ and $a_{R c}$ parameters,

$d_{\text {prdop }} \quad-$ limit values of $a_{R b}$ and $a_{R c}$ parameters for $\theta_{i}$ instantaneous value,

$\mu \quad-$ mean value,

$\sigma \quad-$ standard deviation,

$i \quad-$ number of the next measurement, $a<3, m=\frac{\Theta_{\max }}{\Delta \Theta_{s r}}$,

$\theta_{\max } \quad$ service life.

The basis of formulas (7) and (8) constitutes Linderberg - Levy statement concerning the limit of a summary diagnostic signal [4].

\section{Threshold characteristic of diagnostic signal, the limit value of a summary diagnostic signal}

For each operating time of $\Theta$ technical object $d_{p r}(\Theta)$, threshold diagnostic signal is established. Its course within $\Theta$ time function is called a threshold characteristic (7). A threshold characteristic is used for representing the maximum value of summary diagnostic signal in the function of duration of $\Theta$ technical object operation.

$d_{d o p}$ (8) limit value is the largest value that the signal can achieve after a $\Theta_{\max }$ time, corresponding to service life.

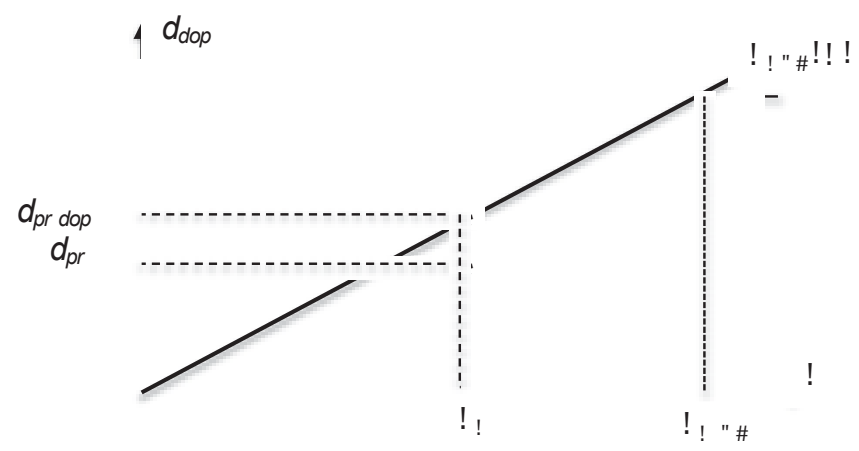

Fig. 1. Determination of the value of $d_{d o p}$ on the basis of $d_{d o p}$ threshold characteristics

\section{Instantaneous threshold values of diagnostic signal, limit values and threshold limit values of diagnostic signals}

Tables $1 \mathrm{a}, 1 \mathrm{~b}$ and $2 \mathrm{a}, 2 \mathrm{~b}$ show the instantaneous threshold values of diagnostic signals, limit values and diagnostic signal limit values. On their basis, the moments when parametric and 
temporary damage occurred were established. Parametric damage occurs when, for the course of $a_{R b}$ parameter ' $i$ ' at any time, $d_{p r}(\theta)>d_{p r d o p}$. Temporary damage occurs when, for the course of $a_{R c}$ parameter ' $i$ ' at any time, $d_{p r}(\theta)>d_{\text {prdop. }}$. The number of $m_{b}$ and $m_{c}$ parameter and instantaneous damage constitutes the basis for establishing $R_{b}^{*}$ and $R_{c}^{*}$ estimates of reliability and $R(t)=R\left(R_{b}^{*}, R_{c}^{*}\right)$ reliability characteristics.

Tab. 1a. The parameter values of $a_{R b}$ technical condition and $a_{R c}$ state regulation for the No. 3 [7] team, the mean and standard deviation as well as threshold values and threshold limits (formulas 7, 8, 9), and also identified numbers of parametric and temporary damage

\begin{tabular}{|c|c|c|c|c|c|c|c|}
\hline No. & $\theta$ & $a_{R b}$ & $a_{R c}$ & $\mu_{a_{R b}}$ & $\mu_{a_{R c}}$ & $\sigma_{a_{R b}}$ & $\sigma_{a_{R c}}$ \\
\hline 1 & 8329 & 9.68 & -5.00 & & & & \\
\hline 2 & 8354 & -497.72 & 3335.29 & & & & \\
\hline 3 & 8401 & 207.70 & 702.68 & -93.44 & 1344.33 & 363.85 & 1760.16 \\
\hline 4 & 8442 & 6062.20 & -483.49 & 1445.47 & 887.37 & 3092.13 & 1703.14 \\
\hline 5 & 8487 & 9347.85 & -4411.58 & 3025.94 & -172.42 & 4434.01 & 2791.29 \\
\hline 6 & 8531 & 936.85 & 1000.00 & 2677.76 & 22.99 & 4056.57 & 2542.07 \\
\hline 7 & 8578 & 1116.52 & 1296.45 & 2454.73 & 204.91 & 3749.85 & 2369.97 \\
\hline 8 & 8602 & 1322.84 & -1059.28 & 398.30 & -116.03 & 3494.67 & 2239.23 \\
\hline 9 & 8648 & -498.19 & 2100.00 & 2000.86 & 275.01 & 3400.64 & 2203.58 \\
\hline 10 & 8675 & -7245.89 & -5938.46 & 1076.19 & -346.34 & 4339.32 & 2859.53 \\
\hline 11 & 8699 & -6380.60 & 2187.06 & 398.30 & -116.03 & 4690.59 & 2818.28 \\
\hline 12 & 8744 & 739.93 & -503.03 & 426.77 & -148.28 & 4473.39 & 2689.45 \\
\hline 13 & 8769 & 1080.59 & -909.55 & 477.06 & -206.84 & 4286.78 & 2583.59 \\
\hline 14 & 8819 & 1421.26 & 121.17 & 544.50 & -183.41 & 4126.33 & 2483.78 \\
\hline 15 & 8838 & 317.78 & 3739.36 & 529.39 & 78.11 & 3976.66 & 2598.92 \\
\hline 16 & 8861 & 1724.83 & -4025.47 & 604.10 & -178.36 & 3853.42 & 2712.30 \\
\hline 17 & 8909 & -8079.52 & -12150.30 & 93.30 & -882.60 & 4284.44 & 3915.07 \\
\hline 18 & 8937 & -4214.94 & 1807.99 & -146.05 & -733.12 & 4278.76 & 3850.76 \\
\hline 19 & 8982 & -350.37 & 5986.19 & -156.80 & -379.47 & 4158.47 & 4047.32 \\
\hline 20 & 9006 & 5891.05 & 11246.45 & 145.59 & 201.82 & 4267.50 & 4719.83 \\
\hline 21 & 9029 & 8737.81 & -3385.51 & 554.75 & 31.00 & 4562.51 & 4666.45 \\
\hline 22 & 9079 & 5106.85 & 1862.98 & 761.66 & 114.27 & 4557.10 & 4570.70 \\
\hline 23 & 9097 & 12365.21 & -4594.70 & 1266.16 & -90.47 & 5067.27 & 4572.29 \\
\hline 24 & 9121 & 9059.11 & 9206.48 & 1590.87 & 296.91 & 5204.92 & 4857.81 \\
\hline 25 & 9235 & 417.53 & 1927.12 & 1543.93 & 362.11 & 5100.73 & 4766.69 \\
\hline 26 & 9256 & 5317.39 & 669.32 & 1689.07 & 373.93 & 5052.17 & 4670.77 \\
\hline 27 & 9278 & 10217.25 & -2086.11 & 2004.93 & 282.82 & 5218.85 & 4604.47 \\
\hline 28 & 9322 & -920.42 & 4610.51 & 1900.45 & 437.38 & 5151.05 & 4591.82 \\
\hline 29 & 9333 & 3315.09 & 340.53 & 1949.23 & 434.04 & 5065.05 & 4509.11 \\
\hline 30 & 15182 & -4.50 & -2.04 & 1884.11 & 419.50 & 4989.72 & 4431.40 \\
\hline 31 & 15206 & -21559.13 & -12432.92 & 1127.87 & 4.91 & 6464.98 & 4930.65 \\
\hline 32 & 15312 & 155.01 & 642.05 & 1097.47 & 24.82 & 6362.17 & 4851.78 \\
\hline 33 & 15352 & -2103.25 & 2357.73 & 1000.48 & 95.51 & 6286.72 & 4792.60 \\
\hline 34 & 15388 & 1836.98 & -83.44 & 1025.08 & 90.25 & 6192.39 & 4719.53 \\
\hline 35 & 15407 & -23705.14 & 1022.12 & 318.50 & 116.87 & 7395.38 & 4652.27 \\
\hline
\end{tabular}


The Assessment of Object Usability on the Basis of Instantaneous Values of Technical Condition and Regulation...

Tab. 1b. The parameter values of $a_{R b}$ technical condition and $a_{R c}$ state regulation for the No. 3 [7] team, the mean and standard deviation as well as threshold values and threshold limits (formulas 7, 8, 9), and also identified numbers of parametric and temporary damage

\begin{tabular}{|c|c|c|c|c|c|c|c|c|}
\hline No. & $d_{p r a_{R h}}$ & $d_{{d o p a_{R_{h}}}}$ & $d_{p r d o p a_{R_{h}}}$ & $d_{p r a_{R_{c}}}$ & $d_{\text {dopa }_{R_{\text {Re }}}}$ & $d_{\text {prdopa }_{R_{r}}}$ & $m_{a_{R b}}$ & $m_{a_{R c}}$ \\
\hline \multicolumn{9}{|l|}{1} \\
\hline \multicolumn{9}{|l|}{2} \\
\hline 3 & 1610 & 2253 & 316 & 13179 & 23792 & 3331 & 1 & 1 \\
\hline 4 & 24335 & 4806543 & 676281 & 13768 & 2918813 & 410677 & 0 & 0 \\
\hline 5 & 44874 & 9313915 & 1317453 & 17862 & -43747 & -6188 & 0 & 1 \\
\hline 6 & 45876 & 8152134 & 1159098 & 18818 & 468258 & 66578 & 0 & 0 \\
\hline 7 & 46947 & 7282200 & 1041112 & 20245 & 930147 & 132980 & 0 & 0 \\
\hline 8 & 32840 & 1807075 & 259074 & 18072 & 15619 & 2239 & 0 & 1 \\
\hline 9 & 48614 & 6475298 & 933306 & 22307 & 1173323 & 169115 & 0 & 0 \\
\hline 10 & 51928 & 4145500 & 599370 & 23665 & -615127 & -88937 & 0 & 1 \\
\hline 11 & 51052 & 2173069 & 315059 & 26765 & 98639 & 14301 & 0 & 1 \\
\hline 12 & 51610 & 2151272 & 313512 & 26170 & -21828 & -3181 & 0 & 1 \\
\hline 13 & 52570 & 2382777 & 348243 & 25257 & -253912 & -37109 & 0 & 1 \\
\hline 14 & 53941 & 2457796 & 361255 & 25313 & -168119 & -24711 & 0 & 1 \\
\hline 15 & 54145 & 2526026 & 372084 & 31368 & 727183 & 107114 & 0 & 0 \\
\hline 16 & 55907 & 2869016 & 423706 & 29694 & -153999 & -22743 & 0 & 1 \\
\hline 17 & 54582 & 1071481 & 159097 & 33423 & -2334376 & -346616 & 0 & 1 \\
\hline 18 & 51831 & 248178 & 36966 & 35816 & -1883627 & -280566 & 1 & 1 \\
\hline 19 & 51400 & 194813 & 29163 & 45716 & -579473 & -86747 & 1 & 1 \\
\hline 20 & 60166 & 1267703 & 190282 & 67360 & 1544985 & 231902 & 0 & 0 \\
\hline 21 & 74374 & 2829046 & 425724 & 64804 & 953920 & 143549 & 0 & 0 \\
\hline 22 & 80881 & 3436695 & 520029 & 66829 & 1201207 & 181763 & 0 & 0 \\
\hline 23 & 102027 & 5481215 & 831044 & 63703 & 497517 & 75432 & 0 & 0 \\
\hline 24 & 114677 & 6824919 & 1037502 & 78521 & 1982326 & 301347 & 0 & 0 \\
\hline 25 & 115109 & 5598055 & 861634 & 80553 & 1907035 & 293524 & 0 & 0 \\
\hline 26 & 121199 & 6243075 & 963098 & 81171 & 1983954 & 306058 & 0 & 0 \\
\hline 27 & 135487 & 7495583 & 1159067 & 79413 & 1723037 & 266439 & 0 & 0 \\
\hline 28 & 134983 & 7042725 & 1094205 & 85139 & 2202768 & 342237 & 0 & 0 \\
\hline 29 & 138356 & 7529928 & 1171280 & 85434 & 2268873 & 352923 & 0 & 0 \\
\hline 30 & 138513 & 786940 & 199122 & 85400 & 343033 & 86799 & 0 & 0 \\
\hline 31 & 142950 & 678027 & 171835 & 82510 & 258631 & 65546 & 0 & 1 \\
\hline 32 & 143089 & 687276 & 175393 & 83132 & 266899 & 68113 & 0 & 1 \\
\hline 33 & 141359 & 680173 & 174034 & 85746 & 295095 & 75505 & 0 & 1 \\
\hline 34 & 143175 & 711781 & 182548 & 85627 & 298148 & 76465 & 0 & 1 \\
\hline 35 & 142403 & 547957 & 140706 & 86660 & 313504 & 80502 & 1 & 1 \\
\hline
\end{tabular}


Tab. 2a. The parameter values of $a_{R b}$ technical condition and $a_{R c}$ state regulation for the No. 4 [7] team, the mean and standard deviation as well as threshold values and threshold limits (formulas 7, 8, 9), and also identified numbers of parametric and temporary damage

\begin{tabular}{|c|c|c|c|c|c|c|c|}
\hline No. & $\theta$ & $a_{R b}$ & $a_{R c}$ & $\mu_{a_{p b}}$ & $\mu_{a_{R C}}$ & $\sigma_{a_{R b}}$ & $\sigma_{a_{R c}}$ \\
\hline 1 & 8315 & -0.25 & 7.23 & & & & \\
\hline 2 & 8340 & 3348.23 & -24272.14 & & & & \\
\hline 3 & 8365 & -610.19 & 1958.90 & 912.60 & -7435.34 & 2131.26 & 14613.72 \\
\hline 4 & 8437 & 730.49 & -2584.31 & 867.07 & -6222.58 & 1742.54 & 12176.08 \\
\hline 5 & 8447 & 6115.71 & 5261.78 & 1916.80 & -3925.71 & 2790.52 & 11729.06 \\
\hline 6 & 8484 & 595.73 & -1865333.27 & 1696.62 & -314160.30 & 2553.52 & 759988.87 \\
\hline 7 & 8509 & 817.05 & 2356.21 & 1570.97 & -268943.66 & 2354.62 & 704010.69 \\
\hline 8 & 8567 & -1471.58 & 110.33 & 1022.97 & 4972.12 & 2430.91 & 658692.16 \\
\hline 9 & 8591 & -1191.02 & 1933662.85 & 926.02 & 5685.28 & 2408.51 & 949925.15 \\
\hline 10 & 8615 & 2063.22 & 2643.62 & 1039.74 & 5381.12 & 2299.06 & 895598.53 \\
\hline 11 & 8660 & 855.23 & 882.14 & 1022.97 & 4972.12 & 2181.79 & 849640.45 \\
\hline 12 & 8699 & 3837.62 & -3259.92 & 1257.52 & 4286.12 & 2233.31 & 810103.87 \\
\hline 13 & 8735 & 2387.92 & 1066.48 & 1344.47 & 4038.45 & 2161.09 & 775615.92 \\
\hline 14 & 8756 & 13020.62 & 0.00 & 2178.49 & 3749.99 & 3748.21 & 745188.45 \\
\hline 15 & 8780 & 3127.65 & 0.00 & 2241.76 & 3499.99 & 3620.17 & 718082.21 \\
\hline 16 & 8826 & 4156.69 & -81.57 & 2361.45 & 3276.14 & 3530.03 & 693733.91 \\
\hline 17 & 8850 & 31790.12 & 152.22 & 4092.54 & 3092.38 & 7913.67 & 671705.39 \\
\hline 18 & 8900 & 1470.90 & -75.05 & 3946.90 & 2916.42 & 7702.22 & 651650.38 \\
\hline 19 & 8924 & 843.38 & 0.00 & 3783.55 & 2762.92 & 7519.00 & 633290.69 \\
\hline 20 & 8949 & 1785.12 & 70713.50 & 3683.63 & 6160.45 & 7332.09 & 616587.13 \\
\hline 21 & 8995 & 1293.94 & 1320.91 & 3569.84 & 5929.99 & 7165.43 & 600975.72 \\
\hline 22 & 9017 & -161058.82 & -101107.81 & -3913.28 & 1064.64 & 35788.75 & 586936.06 \\
\hline 23 & 9067 & 15331.09 & 1231.52 & -3076.57 & 1071.90 & 35195.41 & 573441.47 \\
\hline 24 & 9091 & 3278.62 & 795.97 & -2811.77 & 1060.40 & 34446.23 & 560836.83 \\
\hline 25 & 9115 & -1066.03 & 54562.62 & -2741.94 & 3200.49 & 33722.77 & 549132.68 \\
\hline 26 & 9243 & 0.00 & 0.00 & -2636.48 & 3077.39 & 33045.81 & 538038.31 \\
\hline 27 & 9256 & -147124.16 & 4673.81 & -7987.88 & 3136.52 & 42699.36 & 527590.06 \\
\hline 28 & 9338 & -3521.76 & 331.66 & -7828.37 & 3036.34 & 41909.67 & 517727.97 \\
\hline 29 & 9362 & 8083.25 & -1955.42 & -7279.70 & 2864.21 & 41260.41 & 508399.62 \\
\hline 30 & 9386 & 401.57 & 1089.70 & -7023.65 & 2805.06 & 40567.03 & 499557.31 \\
\hline 31 & 15247 & 13.38 & 0.69 & -6796.65 & 2714.60 & 39905.20 & 491161.05 \\
\hline 32 & 15253 & 5199.87 & 161330.29 & -6421.76 & 7671.34 & 39313.53 & 483987.07 \\
\hline 33 & 15353 & 566090.28 & -7558.62 & 10927.09 & 7209.83 & 106909.68 & 476372.13 \\
\hline 34 & 15416 & 1498.93 & 1089.45 & 10649.79 & 7029.82 & 105289.80 & 469100.02 \\
\hline 35 & 15427 & 146.29 & -575.89 & 10349.69 & 6812.51 & 103745.05 & 462151.80 \\
\hline
\end{tabular}


The Assessment of Object Usability on the Basis of Instantaneous Values of Technical Condition and Regulation...

Tab. 2b. The parameter values of $a_{R b}$ technical condition and $a_{R c}$ state regulation for the No. 4 [7] team, the mean and standard deviation as well as threshold values and threshold limits (formulas 7, 8, 9), and also identified numbers of parametric and temporary damage

\begin{tabular}{|c|c|c|c|c|c|c|c|c|}
\hline No. & $d_{p r a_{R_{b}}}$ & $d_{d_{d o p a_{R_{b}}}}$ & $d_{\text {prdopa }_{R_{b}}}$ & $d_{p_{a_{R_{c}}}}$ & $d_{d o p a_{R_{c}}}$ & $d_{\text {prdopa }_{R_{c}}}$ & $m_{a_{R b}}$ & $m_{a_{R c}}$ \\
\hline \multicolumn{9}{|l|}{1} \\
\hline \multicolumn{9}{|l|}{2} \\
\hline 3 & 13812 & 23715 & 3306 & 53629 & 64099 & 8937 & 1 & 1 \\
\hline 4 & 13924 & 2405363 & 338234 & 48166 & -13579108 & -1909449 & 0 & 1 \\
\hline 5 & 28303 & 7453180 & 1049283 & 59052 & -12113524 & -1705382 & 0 & 1 \\
\hline 6 & 28944 & 6370896 & 900845 & 3699793 & -961247643 & -135920417 & 0 & 1 \\
\hline 7 & 29686 & 6378720 & 904609 & 3705306 & -887708352 & -125891839 & 0 & 1 \\
\hline 8 & 28811 & 3614599 & 516104 & 5628965 & 126215043 & 18021405 & 0 & 0 \\
\hline 9 & 30011 & 3587295 & 513641 & 8600494 & 186032247 & 26636717 & 0 & 0 \\
\hline 10 & 32208 & 4210267 & 604524 & 8550205 & 181927134 & 26121704 & 0 & 0 \\
\hline 11 & 32961 & 3880990 & 560156 & 8508509 & 166059204 & 23967878 & 0 & 0 \\
\hline 12 & 38299 & 4610157 & 668396 & 8470280 & 155208796 & 22502689 & 0 & 0 \\
\hline 13 & 40854 & 4884331 & 711077 & 8442069 & 148292634 & 21588936 & 0 & 0 \\
\hline 14 & 72572 & 8435348 & 1230998 & 8417220 & 146825833 & 21426783 & 0 & 0 \\
\hline 15 & 75689 & 8968856 & 1312443 & 8395861 & 144112389 & 21088446 & 0 & 0 \\
\hline 16 & 80144 & 8942514 & 1315444 & 8377225 & 135025153 & 19862200 & 0 & 0 \\
\hline 17 & 167460 & 16362425 & 2413458 & 8361107 & 132986273 & 19615475 & 0 & 0 \\
\hline 18 & 169077 & 14967935 & 2220244 & 8346651 & 124860357 & 18520953 & 0 & 0 \\
\hline 19 & 170211 & 14835100 & 2206474 & 8333846 & 123286197 & 18336767 & 0 & 0 \\
\hline 20 & 172043 & 14809437 & 2208828 & 8395593 & 134435191 & 20051009 & 0 & 0 \\
\hline 21 & 173475 & 13856135 & 2077266 & 8386580 & 127924621 & 19178033 & 0 & 0 \\
\hline 22 & 417500 & -7770132 & -1167721 & 8282345 & 110126945 & 16550244 & 1 & 0 \\
\hline 23 & 435613 & -4487481 & -678133 & 8275040 & 105284369 & 15910223 & 1 & 0 \\
\hline 24 & 438772 & -3872829 & -586798 & 8268034 & 104386541 & 15816301 & 1 & 0 \\
\hline 25 & 437293 & -3911536 & -594227 & 8317002 & 111347098 & 16915480 & 1 & 0 \\
\hline 26 & 436955 & -2463143 & -379447 & 8310416 & 97472781 & 15015682 & 1 & 0 \\
\hline 27 & 449944 & -17960124 & -2770648 & 8309001 & 98682058 & 15223352 & 1 & 0 \\
\hline 28 & 446101 & -15991512 & -2488812 & 8303694 & 92603886 & 14412251 & 1 & 0 \\
\hline 29 & 455471 & -15030959 & -2345331 & 8296509 & 92053793 & 14363460 & 1 & 0 \\
\hline 30 & 455875 & -14864785 & -2325348 & 8292716 & 91774167 & 14356539 & 1 & 0 \\
\hline 31 & 455852 & 69515 & 17665 & 8288160 & 25853648 & 6569843 & 1 & 1 \\
\hline 32 & 461676 & 90628 & 23039 & 8459016 & 27865696 & 7083924 & 1 & 1 \\
\hline 33 & 2203042 & 9293133 & 2377958 & 8447573 & 28011903 & 7167779 & 0 & 1 \\
\hline 34 & 2203912 & 9436835 & 2424637 & 8444913 & 28319623 & 7276255 & 0 & 1 \\
\hline 35 & 2203531 & 9621183 & 2473767 & 8440819 & 28735330 & 7388332 & 0 & 1 \\
\hline
\end{tabular}


On the basis of analysis presented in Tab. $1 \mathrm{a}, 1 \mathrm{~b}$ and $2 \mathrm{a}, 2 \mathrm{~b}$ it can be concluded that, during the study, $m_{R b}$ parametric and $m_{R c}$ instantaneous damage occurred.

\section{Summary}

The problem of determination of reliability for each individual object based on the number of parametric and instantaneous failures (before the onset of catastrophic damage) is still open. Its solution is largely dependent on the identification of the number of parametric and instantaneous damage, which is especially difficult when a relatively small number of measurements are available. The diagnostic threshold and the exceedance of diagnostic threshold (failure) are determined on the basis of statistical processing of obtained measurements. $\mu+\sigma, \mu+2 \sigma, \mu+3 \sigma$ thresholds (where $\mu$ - average value of measurements, $\sigma$ - standard deviation) are imprecise, because they are solely based on statistics. Another threshold determined on the basis of Lidenberg - Levy statement (7 and 8) is more accurate, because it includes additional information such as: for the early operation of the object, the use amounts to zero and, for $\theta_{\max }$ service life, the use defined by direct methods amounts to $d_{d o p}$. The result of the new approach is that, for example, for $\theta=$ 8401 hours, the adoption of $(\mu+\sigma)$ threshold does not show a parametric damage, whereas the acceptance of $d_{\text {prdop }}$ threshold also indicates damage.

\section{References}

[1] Borowczyk, H., Lindstedt, P., Manerowski, J., Permises for a practical computer - aided parametric method of evaluation of the technical object reliability, Journal of KONES, Vol. 16, No. 2, Warsaw 2009.

[2] Cempel, C., Teoria i inżynieria systemów, ITE - PIB, Radom 2006.

[3] Lindstedt, P., The method of complex worthiness assessment of an engineering object in the proces of its use and service, Solid State Phenomena, Vol. 144, Trans Tech Publications, Switzerland 2009.

[4] Lindstedt, P., Borowczyk, H., Magier, J., Badania możliwości kompleksowego diagnozowania uktadu tożyskowania na podstawie informacji uzyskanej $z$ metod funkcjonalnej, tribologicznej, wibroakustycznej, Projekt badawczy KBN Nr 5T12D01122, sprawozdanie ITWL Nr 1371/50, Wyd. ITWL, Warszawa 2003.

[5] Lindstedt, P., Sudakowski, T., Method of prediction of reliability characteristics of a pumping station on the base of diagnostic information, Journal of KONBiN 2(5)2008, ITWL, Warszawa 2008.

[6] Sotskow, B. S., Niezawodność elementów i urzadzeń automatyki, WNT, Warszawa 1973.

[7] Sudakowski, T., Permises of operational method of calculation of reliability of machines on the base of parametric and momentary symptoms of damage, Acta Mechanica et Automatica, Vol. 3, No. 4, Bialystok 2009. 